\title{
BENZODIAZEPINE USE IN BELGIAN NURSING HOMES: A CLOSER LOOK INTO INDICATIONS AND DOSAGES.
}

\author{
Authors \\ Jolyce Bourgeois PharmD ${ }^{1}$, Monique M. Elseviers MSc PhD ${ }^{1,2}$, Majda Azermai MScN ${ }^{1}$, Luc Van \\ Bortel MD PhD ${ }^{1}$, Mirko Petrovic MD PhD ${ }^{1,3}$, Robert R. Vander Stichele MD PhD ${ }^{1}$ \\ ${ }^{1}$ Heymans Institute of Pharmacology, Ghent University, Ghent, Belgium \\ ${ }^{2}$ Department of Nursing Science, University of Antwerp, Antwerp, Belgium \\ ${ }^{3}$ Service of Geriatrics, Ghent University Hospital, Ghent, Belgium
}

\section{Correspondence}

Jolyce Bourgeois

Ghent University- Heymans institute

De Pintelaan 185 (1 blok B)

9000 Ghent

Key words: $\quad$ benzodiazepines; aged ; drug utilisation; pharmacoepidemiology 


\title{
Abstract
}

\begin{abstract}
AIM:
(i)To describe the prevalence of benzodiazepine use in Belgian nursing homes, with specific attention to indications and dosages.

(ii)To compare actual and recommended dosages of benzodiazepines for anxiety and insomnia.

(iii)To explore the risk profile for chronic benzodiazepine use in institutionalised older adults.
\end{abstract}

\section{METHODS:}

Medication charts of 1730 residents from 76 nursing homes in Belgium were collected and analysed, using the ATC classification. Drug name, indication and daily dosage were recorded. From authoritative international sources, we extracted for each drug and each indication a daily dosage recommended not to exceed in older adults, for comparison with observed actual dosages.

\section{RESULTS:}

Among the chronic BZD/Z users ( $50 \%$ of the residents), the leading indication was 'insomnia' (59\% of the users) followed by 'anxiety' (17\%) and 'unrest' (10\%). In the chronic prescriptions of BZD/Zs indicated for insomnia, the actual daily dose exceeded the geriatric upper limit: with lormetazepam in 95\%,zolpidem in $82 \%$, zopiclone in $78 \%$ and lorazepam in $35 \%$ of the prescriptions. In anxiety, daily doses also exceeded the limit but not to the same extend.

Multivariate analysis showed BZD/Z use was positively associated with pain (OR 1.58 CI95\% 1.27-1.97), constipation (OR $1.43 \mathrm{Cl}$ C5\% 1.16-1.76) and depression (OR 1.68 CI95\% 1.35-2.08). Residents with dementia were less likely of receiving a BZD/Z (OR $0.60 \mathrm{CI} 95 \%$ 0.48-0.74).

\section{CONCLUSION:}

Efforts to reduce the use of BZD/Zs in nursing homes should concentrate on insomnia, with interventions aimed to reduce too high prevalence of chronic use and too high daily dosages in this indication. 


\section{INTRODUCTION}

Benzodiazepine utilisation in older adults is high, with intake rates varying from $28 \%$ to $55 \%$ in European nursing homes [1-4].

Benzodiazepines are mainly indicated for the short-term treatment of insomnia and anxiety $[5,6]$. Long-term use of benzodiazepines is discouraged in guidelines $[5,7,8]$ because of the lack of effectiveness after 4 weeks $[9,10]$, the increased risk of dependence and abuse, and withdrawal syndromes [11, 12]. Moreover, it has been hypothesised that long-term use might have a detrimental effect on cognition and a potential acceleration of cognitive impairment [13-15].

High benzodiazepine utilisation in older adults is especially worrying, since age-related pharmacokinetic-and dynamic alterations may lead to an increased risk of amnesia, confusion, sedation $[16,17]$, hangover effects [18, 19] and consecutive risk of falling [20].

International drug formularies [21-23] recommend dose reduction when using benzodiazepines in older adults. Moreover, in several attempts to develop prescribing quality indicators, upper limits for dosages in older adults were established for some benzodiazepines as part of lists with explicit criteria for inappropriate prescribing [2426]. In addition, benzodiazepines are the most recurring group of drugs in terms of chronic prescribing and in terms of inappropriate psychotropic polypharmacy.

Numerous studies have explored benzodiazepine utilisation in older adults, but they are often limited to the description of crude utilisation data, without looking deeper into active substances, dosages and indications. Previous articles indicate the need for documentation of indications to proper evaluate the appropriateness of psychotropic drug use $[27,28]$. Therefore, the aim of this study was to describe the prevalence of benzodiazepine use in Belgian nursing homes, with attention to indications and dosages for each of the commonly used drugs. Furthermore, we compared actual dosages with recommended dosages in older adults and explored the risk profile for chronic benzodiazepine use. 


\section{METHODS:}

Data for this secondary analysis study was obtained from a multicentre study, investigating the overall drug utilisation in Belgian nursing homes. A detailed description of the methods and findings of this study was published elsewhere $[1,29]$.

\section{Setting}

Belgium has a mixed, public/private health care system. The system is fee for service. An essential principle of the Belgian health care system is the patient's freedom of choice between a wide range of independent care providers without listing system. In particular, the Belgian long-term residential care structure consists of residential and/or nursing homes for older people, which offer a home replacement with or without nursing care. Governance of nursing homes for older people is either public (community health services) or private (predominantly non-profit). Each nursing home has a medical coordinator who is a general practitioner, additionally educated in care for older people. Most of the residents are still treated by their former GP, with an average of 32 visiting GPs per nursing home. Thereby, the GP has the responsibility for the treatment and medication policy. Periodic reassessment of the medication charts (i.e. a regime for monitoring and discontinuation of therapy) is not mandatory.

\section{Data collection}

The PHEBE study (Prescribing in Homes for the Elderly in BElgium) was a cross-sectional, descriptive study of a representative, stratified random sample of 76 Belgian nursing homes. Data collection at resident level included administrative, clinical and medication data. To score the activities of daily living (ADL), we used the Katz scale[30] which is a mandatory instrument in Belgian nursing homes. The progression of disorientation as proxy for dementia severity was also scored by this instrument, ranging from a score 1 (no dementia) to 5 (severe dementia).

For collecting clinical data, a checklist with 28 items, focusing on clinical problems (i. e. diseases with a clear cut diagnosis such as COPD, cardiovascular diseases,...) and on care problems (i.e problems with a predominant nursing care burden such as incontinence, pain, risk of falling,...) was send to the general practitioner (GP) of each included resident. The 28-item checklist of clinical conditions was ad hoc designed for this study, with the items selected 
based on existing prescribing quality indicators for the elderly (BEERS, BEDNURS, ACOVE). It was pilot tested in two nursing homes.

The GP received a printout of the medication chart for verification of the medication use, and was asked to tick a predefined list of main indications for each medication. Residents, considered by their GP as having a palliative status were excluded from the analysis.

\section{Classification of benzodiazepines}

Benzodiazepines (BZD), a group of psychoactive drugs with sedative, hypnotic, anxiolytic, anticonvulsant, muscle relaxant and amnesic action [5] were coded according to the Anatomical Therapeutic and Chemical classification [31]. We investigated the benzodiazepines, available on the Belgian pharmaceutical market of the ATC classes hypnotics (N05CD), anxiolytics (N05BA) and also the related z-drugs (N05CF). This classification is not strictly linked to the clinical indication, as most of the benzodiazepines have a mix of different pharmacological actions.

Clonazepam (N03AE01) mostly used for the indications 'restless legs' and 'epilepsy', and tetrazepam (M03BX07), used as a muscle relaxant, were not included in this study. Duplicate use therapy was defined as the concomitant use of 2 or more different benzodiazepines or z-drugs (BZD/Z). The focus of this study was chronic use, which was defined as daily use for at least 3 months. We analysed 2 levels of describing BZD/Z use: the prescription (medication) and the resident level. Indications were analysed at resident and prescription level and dosages at prescription level only.

\section{$\underline{\text { Indications and dosages }}$}

The indication of each BZD/Z drug was obtained from the GP who ticked an item on a predefined list of indications: anxiety, insomnia, unrest, epilepsy, muscle tension and acute agitation. Only the indications anxiety, insomnia and unrest were analysed in depth, as the other indications were not prevalent enough. Unrest is the symptom targeted by mild sedatives, intended to calm a restless patient. It is to be distinguished from the narcotic sedation used in palliative setting. When a physician ticked 2 or more indications for the same BZD/Z, we classified this as 'multiple indications'. Only BZD/Zs with a minimum frequency of 15 prescriptions were reported in this study. 
The daily dosage of each BZD/Z in each patient was recorded by summing the doses taken at the different moments of intake during one day. Comparison between prescribed daily dosages of a BZD/Z for different indications was made when at least 5 prescriptions for each indication were present. We also analysed the different moments of intake to see fractionation.

Determination of the daily dose recommended not to exceed in older adults.

Reviewing several international pharmaceutical sources with dose recommendations for older adults, we selected 3 international formularia [21-23] and 3 explicit criteria for inappropriate prescribing for older adults [24-26] that mentioned detailed information per active substance. These sources were the basis of selecting 'the geriatric upper limit' i.e. daily dose recommended not to exceed in the geriatric population. We focused on specific doses associated with the indication 'insomnia' and 'anxiety' and selected the dose which was advised by the majority of the sources. Specific dose recommendations for sedative action in the indication of unrest were not found in these sources.

Only for lorazepam, we found a dose separate for insomnia and for anxiety. For alprazolam, bromazepam and prazepam, these sources only mentioned a dose for the indication of anxiety. For the indication of insomnia, we found specific dose recommendations for lormetazepam, zolpidem and zopiclone. The recommendations retrieved from the various sources, the selected geriatric upper limit, and the relation with the Defined Daily Dose(DDD) and diazepam equivalent are presented in Box 1.

To calculate the percentage of prescriptions exceeding the 'geriatric upper limit', we compared the actual daily dosages for each prescription identified in the study with the geriatric upper limit.

\section{$\underline{\text { Statistics }}$}

The data was analysed using the statistical package SPSS version 18 . The alpha level of significance was set at $p<$ 0.05 .

In a preliminary analysis investigating BZD and z-drug use separately, we found no differences in residents characteristics. Consequently, all users were concatenated in one "BZD/Z" group for further analysis. 
We used descriptive statistics to explore indications and dosages. To detect differences in prescribed daily doses for different indications, we used non-parametric statistics (medians and the Mann-Whitney U test). To explore a risk profile for BZD/Z use, we compared users and non-users. In univariate analysis, we used $\mathrm{Chi}^{2}$ for dichotomous variables and independent T-tests for continuous variables. For multivariate analysis, we used a stepwise regression model with the statistically significant variables from the univariate analysis. To compare the characteristics of chronic users of BZD/Zs in different indications (anxiety, insomnia, unrest), we used Chi ${ }^{2}$ for dichotomous variables and one way ANOVA for continuous variables. 


\section{RESULTS}

\section{Description of the study population}

Medication data and clinical information of 1730 residents was included in the analysis. The mean age was 85 (range $60-104$ ) and $78 \%$ was female. In $48 \%$ of the population, the treating physician diagnosed dementia and in $36 \%$ depression (table 1). A combination of these two care problems was seen in $15 \%$ of the residents.

The residents had a mean drug utilisation of 7 chronic medications per resident, ranging from no medication (in less than $1 \%$ of the residents) to 22 medications. The most frequently used drugs were central nervous system drugs with benzodiazepines and z-drugs (BZD/Z), antidepressant, antipsychotic and anti-dementia drug prevalence in respectively $53 \%, 40 \%, 33 \%$ and $8 \%$ of all residents (table 1 ).

Descriptive analysis on resident level: prevalence of BZD/Z users and indications. The prevalence of BZD/Z drug utilisation among Belgian nursing home residents $(n=1730)$ was $53 \%(n=918)$. Chronic use was present in $50 \%(n=859)$ of the residents, and $3 \%$ used a BZD/Z only occasionally. The use of a single chronic BZD/Z was seen in $42 \%$ of the residents, while $8 \%$ had 2 to 3 chronic BZD/Zs on their medication chart (table 2).

Among the chronic users, using a single BZD/Z ( $n=729)$, indication was missing in 126 residents. An analysis of the characteristics of residents with missing indication revealed no significant differences. Hence, the distribution of indications was extrapolated to the group of chronic users of a single BZD/Z.

The leading indication was insomnia (59\%) followed by anxiety (17\%), unrest (10\%), and "other indications"(4\%); the use of one BZD/Z for multiple indications was $10 \%$ (Table 2 ). When a resident received two or three chronic BZD/Zs, there was mostly a different indication for each of the prescribed BZD/Z, most often a mix of anxiety, insomnia or unrest. 
Descriptive analysis at prescription level: prevalence and dose analysis per indication

The 859 residents on chronic BZD/Zs received a total of 1001 chronic BZD/Z prescriptions for different indications (table 3).

On a total of 448 chronic prescriptions for insomnia, physicians prescribed 16 different BZD/Z drugs: 46\% hypnotics (N05CD) and 27\% z-drugs (N05CF), but also 27\% anxiolytics (N05BA). The dominant sleeping pill was the hypnotic lormetazepam (38\%), followed by zolpidem (23\%). On a total of 186 prescriptions to treat anxiety, physicians prescribed 13 different BDZ/Zs, predominantly anxiolytics (alprazolam 36\% and lorazepam 27\%). On a total of 94 prescriptions to treat unrest, 16 different BZD/Zs were prescribed with a wide spread of anxiolytics (but predominantly lorazepam $39 \%$ ) and also some typical hypnotics and z-drugs (27\%) (table 3).

When comparing the dosages on the prescriptions of an individual BZD/Z used for different indications, the prescribed daily dosages in prescriptions for insomnia were similar to the dosages in prescriptions for unrest, while for anxiety the daily dosages were higher (table 3). For the treatment of anxiety, the daily dosage is fractionated into 2 to 4 administrations per day in $37 \%$ of these prescriptions. For the treatment of unrest, we saw fractionation in only $8 \%$ and no fractionation for insomnia as all prescriptions mentioned one dose at bedtime.

\section{Compliance with 'the Geriatric Upper Limit'.}

In table 4 we give the percentage of prescriptions with a dose higher than 'the geriatric upper limit'. In the prescriptions for insomnia this limit was exceeded for lormetazepam in 95\%, zolpidem in $82 \%$, zopiclone in $78 \%$ and for lorazepam in $35 \%$ of all chronic prescriptions. In the prescriptions for anxiety the 'geriatric upper limit' was also exceeded but not in such high percentages: for alprazolam in $30 \%$, lorazepam in $12 \%$, bromazepam in $11 \%$ and for prazepam in $5 \%$ of all chronic prescriptions.

\section{Comparison between BZD/Z users and non-users.}

Univariate analysis showed that BZD/Z users had a significantly larger usage of chronic medications and antidepressants; a higher frequency of care problems such as constipation, depression, chronic pain; and a lower frequency of dementia and incontinence. We found no association between BZD/Z use and the physicians' 
perception of the risk of falling, nor with the frequency of clinical problems such as cardiovascular diseases, diabetes and COPD (table 5).

In multivariate analysis, BZD/Z use was more frequent in female residents (OR $1.3295 \% \mathrm{Cl}$ 1.03-1.68) and residents with chronic pain (OR $1.5895 \% \mathrm{Cl} 1.27-1.97$ ), constipation (OR $1.4395 \% \mathrm{Cl} 1.16-1.76$ ) and depression (OR 1.68 $95 \% \mathrm{Cl} 1.35-2.08)$, and less frequent in residents with incontinence $(\mathrm{OR}=0.7195 \% \mathrm{Cl} 0.57-0.88)$ and dementia (OR=0.60 95\%Cl 0.48-0.74 (table 5).

Comparison between BZD/Z users for the different indications.

Depression, chronic medication, antidepressant and antipsychotic use was significantly more present when a resident took a BZD/Z for anxiety rather than for insomnia and unrest. We found no significant differences in the risk profile of residents with BZD/Z use for insomnia versus use for unrest (table 6).

Especially among users with the indication of insomnia, we observed a gradual decrease in BZD/Z use as dementia progressed (figure 1).

Relationship with institutional characteristics

BZD/Z drug use was not associated with institutional characteristics such as private or public facility, size, or staffing. 


\title{
DISCUSSION
}

\author{
ORIGINALITY OF THE STUDY
}

In this observational cross-sectional study of chronic use of benzodiazepines and z-drugs (BZD/Z) in Belgian nursing homes, the prevalence of usage of these drugs has been examined in depth per indication, as well as differences in dosing practices per indication.

We confirmed the high prevalence of chronic BZD/Z use (half of the residents) in this setting, as found in numerous other studies [2, 4, 32]. We found that insomnia was the main indication for chronic use, and was treated at higher dosages than recommended in older adults $[21,23,25,26]$. This finding is not striking, but our study is the first to scientifically confirm the assumption that insomnia is most prevalent for BZD/Z use. We were able to determine interesting elements for a risk profile of BZD/Z use in multivariate analysis, such as a positive associations with female gender, obstipation, depression, chronic pain, and polypharmacy (including polypharmacy with other psychotropics), and negative associations with dementia and incontinence. There was a puzzling absence of association with age, risk of falling, clinical problems, and institutional characteristics.

This study in a large representative sample of Belgian nursing home residents provides long-awaited information on indications and dosages of benzodiazepines [33]. Actual daily dosages were compared to the geriatric upper limit, a pragmatic threshold determined from authoritative international pharmaceutical sources.

\section{STRENGHTS AND LIMITATIONS}

Strength of our study was the substantial and representative sample of Belgian nursing home residents [29]. In addition, in neighbouring European countries [2-4] similar prevalence numbers of benzodiazepine use were found. In the United States [27], there is a lower use of benzodiazepines due to the safety warnings issued in the late '80 and due to specific actions tackling the high use of these drugs (Medicare part D). Another strength of this study is that our data collection was based on reliable recording from primary sources, namely medication charts and 
direct clinical information from the treating GP. Another strong aspect of this study was our attempt to list most of the existing recommendations for older adults regarding dosages of BZD/Zs. However, we did not use an explicit method to extract the geriatric upper limit and we limited ourselves to the most abundantly prescribed BZD/Zs in Belgium. This geriatric upper limit is a threshold based on a pragmatic analysis of different sources, and therefore not a gold standard nor a rigid criteria for inappropriate prescribing.

Another limitation was that we did not use internationally validated criteria to evaluate (severity of) dementia. In this cross-sectional study, we were not able to investigate the distribution of the duration of chronic use, nor it was possible to investigate temporal changes and the relationship between process and outcome. Indications of BZD/Z drugs were collected by interviewing the GP, which may have influenced data reliability. To reduce the complexity of the analysis, we narrowed our in depth analysis of indications to chronic users with only one BZD/Z and therefore only one indication, and disregarded residents on multiple BZD/Zs ( $8 \%$ of all residents) or residents on a BZD/Z with more than one indication ( $10 \%$ of the residents on a single chronic BZD/Z). On top there was a high number of missing indication data (17\%) which might reflect an uncertainty of the treating GPs to discriminate between the indications of anxiety, insomnia, and unrest. This pragmatic approach might have introduced some bias in the estimation of the prevalence.

\section{CRITICAL DISCUSSION OF THE MAIN FINDINGS}

\section{Insomnia}

Our study showed that the number one indication for BZD/Z drugs in this setting was insomnia, and to a far lesser extent anxiety and unrest.

A striking finding was that almost all use of BDZ/Z drugs for insomnia was chronic, which is generally considered to be inappropriate $[25,34]$. In order to avoid chronic prescribing, guidelines such as the British National Formulary and the Belgian drug code $[21,35]$ point out that before prescribing a hypnotic, the cause of the insomnia should be established and, where possible, underlying factors (such as depression or 'restless legs') should be treated [36, 
37]. Establishing a good sleep hygiene is the first choice, but is not easy to implement in nursing homes. When a pharmacological treatment seems necessary, hypnotics should be reserved for short courses $(<3$ weeks) in the acutely distressed and routine/chronic prescribing is undesirable [21].

With regard to the drug choice within the benzodiazepine drug class (with hypnotic, anxiolytic, -sedative, musclerelaxant and amnesic action) in the indication of insomnia, mainly hypnotic benzodiazepines and z-drugs were used, but also the anxiolytics lorazepam and bromazepam.

With regard to dosages within the different indications, we found that especially in patients treated for insomnia, the daily dosages of the hypnotic benzodiazepines, of the z-drugs, and of the anxiolytic lorazepam exceeded the geriatric upper limit. However, in terms of diazepam equivalence, the dosages were still considerably lower than the dosages used when treating patients with anxiety.

It is generally known that older adults need a dose reduction, but clear indication specific information about this reduction is hard to find. Most sources stay vague and point at a dose reduction of $50 \%$ and a slow titration. Hence, it is no surprise that there are no clear guidelines, and that GPs are not aware of geriatric optimal dosing. A comparison of the geriatric upper limit with the Defined Daily Dose (DDD) revealed that for anxiety the two values coincided, but that for insomnia, the geriatric upper limit was half the DDD (BOX 1). This may be one methodological explanation for the high prevalence of exceeding dosages in prescriptions indicated for insomnia. Another explanation is that physicians titrate the dosage upwards when tolerance sets in, as expected for benzodiazepines use. Also, the culprit may be the unavailability of geriatric package dosages. Lormetazepam for example, is on the Belgian market in package doses of 1 or $2 \mathrm{mg}$, and consequently exceeds the required $0,5 \mathrm{mg}$ a day for older adults. This is also the case for the package dosages of zolpidem (only packages of 10mg on the market).

In our study, the hypnotic users, but especially the residents receiving a BZD to treat anxiety were more associated with having a depression and a prescription for an antidepressant. This chronic concomitant use of psychotropic drugs to treat depression is not appropriate in the geriatric population who has already an increased risk of 
interactions and adverse drug reactions. On the one hand, it is not surprising we found an association between depression and BZD/Z use, because depression can be the reason of initiating a BZD/Z drug, definitely when depression is related to a disturbed sleep pattern and anxiety [38]. On the other hand, a study in 2007 revealed that the use of hypnotics was associated with an increased incidence of depression, suggesting hypnotics may be contra indicated when there is a risk for depression [39].

Unexpectedly, we saw a gradual decrease in the use of sleeping pills when dementia progressed, although it is well known that patients with dementia often have nocturnally disturbed sleep [40]. As a sleeping problem is frequently an explicit complaint, uttered by the patient [41], it is possible that prescribing sleeping pills is demand-driven. So, when residents with severe dementia lose the ability to express the need for sleeping pills, their prescription might not get renewed.

\section{Anxiety}

In patients using only a single BZD/Z chronically, the single indication of anxiety was limited to less than 1 in 5 patients. However, this indication was also present in patients using multiple BDZ/Z drugs, or a single BZD/Z drug for multiple indications. Using BZDs chronically to treat mild anxiety is considered to be inappropriate [8]. At the onset of treatment of depression, a benzodiazepine could be used as an adjuvant, as the anti-anxiety effect of some antidepressants can take 2 to 4 weeks [42]. However, to avoid chronic use, this dual therapy should be tapered in time [43].

In this indication, the drugs of choice were exclusively the anxiolytic ATC-class drugs, used in daily dosages higher than the dosages used when indicated for insomnia, but closer to the geriatric upper limit (and to the DDD). It is logical daily dosages are higher for anxiety as they are more frequently dispensed during the day, unlike for sleeping pills, which are administered once daily in the evening.

The indication of anxiety was associated with a more intense polypharmacy, more antidepressants (and more depression), and more antipsychotics. Hence, efforts to withdraw from BDZ/Z drug usage should be seen in the broader context of mental health, and treatment of behavioural and psychological symptoms of dementia. 


\section{Unrest}

A variety of benzodiazepines in different ATC classes were used to treat this indication. The prescribed daily doses of these BZD/Z drugs for the indication 'unrest' were similar to the prescribed daily doses of these BZD/Z drugs used for the treatment of insomnia. Furthermore, we observed no differences in characteristics between a resident using a BZD/Z drug for insomnia and unrest. Sedative action is in this setting considered to provide calming effects (different from the narcotic aim in palliative care context and different from control of acute agitation). This suggests some semantic overlap between the terms "sedative" and "hypnotic" action, not only in literature but also in daily practice.

\section{Risk profile of BDZ/Z drug users}

Our multivariate comparison of users versus non-users revealed a positive associations with care problems such as obstipation and chronic pain, possible causes of irritation and sleeplessness leading to BZD/Z use. The negative association between incontinence and BZD/Z use might be explained by covariance with dementia and the use of nocturnal incontinence material.

The association with polypharmacy (more specifically psychotropic polypharmacy) calls for comprehensive approach to assure the quality of psychotropic pharmacotherapy of mental health in nursing homes [44].

In other studies an association was found between BZD/Z use and risk of falling [20, 45-47]. In this cross-sectional study we could not observe this, possibly because treating physicians failed to perceive the risk of falling as a consequence of BZD/Z use, or because of the multifactorial nature of this association.

We did not find significant associations between BDZ/Z drug use and institutional characteristics (including staffing), contradicting the popular belief that high hypnotic usage is associated with low staffing [48]. 


\section{IMPLICATIONS FOR PRACTICE AND RESEARCH}

The contradiction between recommendations against long-term use, and the high prevalence in older adults has already been often discussed but seldom explained. Prescribers seem to be convinced of the detrimental longterm effects of benzodiazepines in older adults [49]. But it seems very hard to change habitual prescribing and to overcome the fear of possible relapse and withdrawal effects in both prescribers and caregivers as in patients [50].

It is difficult to persuade patients and their physicians to stop chronic use of BDZ/Z drugs. However, a small intervention study in primary care showed that sending a letter from the physician to the BZD/Z user could have a positive impact on successful withdrawal $[51,52]$. Motivation and gradual tapering seems to be the best strategy for discontinuation $[11,53]$.

Previous articles on BZDs supported non-pharmacological ways to solve insomnia and to avoid the initiation of benzodiazepines use [54-56]. More efforts to motivate the residents as well as the care giving staff to do physical exercises and other activities to ameliorate the sleep quality of older adults must be made in order to reduce the persistent sleep problems and sleeping pill use $[57,58]$.

More emphasis should be given to at least avoid high dosages in chronic use for older patients. This study found that prescribers do not pay attention to reduce the dosage according to existing recommendations, especially in patients treated for insomnia. We do not know whether this reluctance indirectly leads to a higher mortality [59], but several studies state the existence of adverse effects, such as cognitive impairment [14, 15] addictive properties and possible withdrawal effects. The pharmaceutical companies should produce packages with appropriate dosages for older adults. But also nurses and pharmacists could play an important role in the correct administration of these drugs in older adults $[60,61]$. 
Future research on benzodiazepines should differentiate between insomnia and anxiety or other indications. Our findings suggest that insomnia, given its high prevalence as primary indication, deserves priority. Efforts to reduce chronic use should concentrate on reducing initiation, chronic use and too high dosages for this indication.

Furthermore, there is a need to strengthen the evidence base for the absence of long-term efficacy and the importance of adverse effects, in order to persuade physicians, nurses, caregivers and the patients of the positive risk benefit balance of discontinuation attempts.

\section{COMPETING INTEREST}

There are no competing interests to declare.

\section{ACKNOWLEDGEMENTS}

We thank prof. Dr. Thierry Christiaens, from the department of family medicine and primary care and Dr. Hans Debruyne, psychiatrist at the Dr. Guislain Centre for Psychiatry for their contribution. 


\section{TABLES AND FIGURES}

TABLE 1: Description of the study population

$\begin{array}{cc}\text { RESIDENT CHARACTERISTICS } & \text { Total } \\ \text { population } \\ \mathrm{n}=1730\end{array}$

Demographical characteristics

Age (mean+range)

Gender (\% female)

$84.8[60-104]$

78.1

\section{Main clinical problems(\%)}

cardiovascular

75.7

Peptic ulcer

24.6

COPD

17.2

Diabetes

16.8

Renal failure

12.6

Hepatic problems

1.4

\section{Main care problems(\%)}

Dementia

47.7

Insomnia

44.0

Constipation

41.9

Incontinence

35.9

Depression

35.7

Chronic pain

35.1

Risk of falling

45.5

Medication information

Number of (mean+range)

Medications

$8.0[0-22]$

Chronic medications

$7.1[0-22]$

Prevalence of overall psychotropic use(\%)

77.5

Antipsychotics

Antidepressants

39.5

BZD/Z

53.1

Anti-dementia drugs 
TABLE 2: Prevalence of users of benzodiazepines and z-drug use (BZD/Z) among 1730 nursing home residents and distribution of chronic users of a single $B D / Z$ per indication.

Prevalence of BZD/ Z use $(n=1730)$

BZD/Z users

$53.1 \%$

Chronic BDZ/Z users

$49.7 \%$

Chronic users of a single BZD/Z $42.1 \%$

Distribution of indications among single chronic BZD/Z users $\left(n=603^{*}\right)$

$\begin{array}{ll}\text { Insomnia } & 58.7 \% \\ \text { Anxiety } & 17.4 \% \\ \text { Unrest } & 10.4 \% \\ \text { Others** } & 3.6 \% \\ \text { Multiple indications } & 9.8 \%\end{array}$

*729 residents receiving a single chronic BZD/Z corrected for 126 missing indications

** Epilepsy, muscle spasm, panic attack 
TABLE 3: Distribution of prescriptions for chronic BZD/Z drug use and median prescribed daily doses per indication and per active substance.

\begin{tabular}{|c|c|c|c|c|c|c|c|c|c|c|}
\hline \multirow[t]{3}{*}{ ATC-DRUG CLASS } & \multicolumn{4}{|c|}{ Chronic prescriptions of BZD/Z } & \multicolumn{5}{|c|}{ Prescribed dialy doses (MEDIAN-RANGE) } & \multirow{3}{*}{$\begin{array}{c}\text { P value } \\
\quad * * *\end{array}$} \\
\hline & \multirow{2}{*}{$\begin{array}{c}\text { TOTAL } \\
\%(n=1001)\end{array}$} & \multirow{2}{*}{$\begin{array}{l}\text { INSOMNIA } \\
\%(n=448)\end{array}$} & \multirow{2}{*}{$\begin{array}{l}\text { ANXIETY } \\
\%(n=186)\end{array}$} & \multirow{2}{*}{$\begin{array}{l}\text { UNREST } \\
\%(n=94)\end{array}$} & \multicolumn{2}{|c|}{ INSOMNIA } & \multicolumn{2}{|c|}{ ANXIETY } & UNREST & \\
\hline & & & & & $\mathrm{mg}$ & $\min -\max$ & $\mathrm{mg}$ & $\min -\max$ & $\operatorname{mg} \min -\max$ & \\
\hline ANXIOLYTICS $=$ N05BA & 48.8 & 26.8 & 96.8 & 73.4 & & & & & & \\
\hline -lorazepam & 22.1 & 19.6 & 26.9 & 39.4 & 1.0 & $0.25-2.50$ & 2.0 & $0.50-7.50$ & $1.25 \quad 0.50-2.50$ & 0.035 \\
\hline -alprazolam & 10.3 & 0.4 & 36.0 & 8.5 & & & 0.5 & $0.07-2.00$ & $0.3750 .13-1.00$ & 0.087 \\
\hline -bromazepam & 4.1 & 4.0 & 4.8 & 5.3 & 4.5 & $3.00-6.00$ & 6.0 & $3.00-12.00$ & & 0.196 \\
\hline -prazepam & 3.3 & 0.0 & 11.8 & 0.0 & & & 30.0 & $5.00-40.00$ & & \\
\hline other & $9.0^{*}$ & 2.8 & 17.3 & 20.2 & & & & & & \\
\hline HYPNOTICS $=$ N05CD & 33.0 & 46.4 & 3.2 & 18.1 & & & & & & \\
\hline -lormetazepam & 26.1 & 37.7 & 2.7 & 12.8 & 2.0 & $0.50-3.00$ & & & $1.750 .50-2.00$ & 0.832 \\
\hline other & $6.9 * *$ & 8.7 & 0.5 & 5.3 & & & & & & \\
\hline Z-DRUGS = N05CF & 18.3 & 26.8 & 0.0 & 8.5 & & & & & & \\
\hline -zolpidem & 16.3 & 22.5 & 0.0 & 7.4 & 10.0 & $2.50-20.00$ & & & $10.05 .00-10.00$ & 0.853 \\
\hline -zopiclone & 1.9 & 4.0 & 0.0 & 1.1 & 7.5 & $3.75-7.50$ & & & & \\
\hline -zaleplon & 0.1 & 0.2 & 0.0 & 0.0 & & & & & & \\
\hline
\end{tabular}


TABLE 4: Percentage of prescriptions exceeding the Geriatric Upper Limit per indication.

\begin{tabular}{llccc}
\hline INDICATION & \multicolumn{1}{c}{ BZD/Z } & \multicolumn{3}{c}{ DOSAGES } \\
& & $\begin{array}{c}\text { Geriatric Upper } \\
\text { Limit* }\end{array}$ & $n^{* *}$ & \%Exceeding*** \\
\hline INSOMNIA & Lormetazepam & $0.5 \mathrm{mg}$ & 169 & 94.7 \\
& Zolpidem & $5 \mathrm{mg}$ & 101 & 82.2 \\
& Lorazepam & $2 \mathrm{mg}$ & 88 & 35.2 \\
& Zopiclone & $3.75 \mathrm{mg}$ & 18 & 77.8 \\
\multirow{5}{*}{ ANXIETY } & Alprazolam & $0.75 \mathrm{mg}$ & 67 & 29.9 \\
& Lorazepam & $3 \mathrm{mg}$ & 50 & 12.0 \\
& Prazepam & $30 \mathrm{mg}$ & 22 & 4.5 \\
& Bromazepam & $10 \mathrm{mg}$ & 9 & 11.1 \\
\hline
\end{tabular}

*Recommendations (see box)

** the number of chronic prescriptions for this specific drug for this indication

*** \% of prescriptions for older adults exceeding the Geriatric Upper Limit 
TABLE 5: Comparison of characteristics between chronic benzodiazepine or z-drug users and non-users $(n=1730)$.

\begin{tabular}{|c|c|c|c|c|c|c|c|}
\hline \multirow[t]{2}{*}{ RESIDENT CHARACTERISTICS } & \multirow{2}{*}{$\begin{array}{c}\text { BZD } / Z \text { user } \\
n=859\end{array}$} & \multirow{2}{*}{$\begin{array}{c}\text { non user } \\
n=871\end{array}$} & \multirow[t]{2}{*}{ P value* } & \multicolumn{2}{|c|}{ UNIVARIATE ** } & \multicolumn{2}{|c|}{ MULTIVARIATE*** } \\
\hline & & & & OR & $95 \% \mathrm{Cl}$ & OR & $95 \% \mathrm{Cl}$ \\
\hline \multicolumn{8}{|l|}{ Demographical } \\
\hline Age (mean+range) & $84.5[60-104]$ & $85.1[60-104]$ & 0.165 & 0.99 & $0.98-1.00$ & & \\
\hline Gender(\% female) & 80.3 & 75.7 & 0.021 & 1.31 & $1.04-1.65$ & 1.32 & $1.03-1.68$ \\
\hline \multicolumn{8}{|l|}{ Main clinical problems(\%) } \\
\hline Cardiovascular & 77.3 & 74.1 & 0.112 & 1.20 & $0.96-1.49$ & & \\
\hline Peptic ulcer & 24.9 & 24.3 & 0.766 & 1.03 & $0.83-1.29$ & & \\
\hline COPD & 18.5 & 15.9 & 0.156 & 1.20 & $0.99-1.54$ & & \\
\hline Diabetes & 15.9 & 17.8 & 0.303 & 0.88 & $0.68-1.13$ & & \\
\hline Renal failure & 11.8 & 13.4 & 0.326 & 0.87 & $0.65-1.15$ & & \\
\hline Hepatic problems & 1.6 & 1.2 & 0.441 & 1.38 & $0.61-3.12$ & & \\
\hline \multicolumn{8}{|l|}{ Main care problems(\%) } \\
\hline Constipation & 46.8 & 36.9 & $p<0.001$ & 1.50 & $1.24-1.82$ & 1.43 & $1.16-1.76$ \\
\hline Risk of falling & 46.4 & 44.5 & 0.421 & 1.08 & $0.89-1.31$ & & \\
\hline Depression & 42.2 & 29.0 & $p<0.001$ & 1.79 & $1.46-2.20$ & 1.68 & $1.35-2.08$ \\
\hline Chronic pain & 42.1 & 27.9 & $p<0.001$ & 1.89 & $1.54-2.31$ & 1.58 & 1.27-1.97 \\
\hline Dementia & 40.1 & 55.5 & $p<0.001$ & 0.54 & $0.44-0.65$ & 0.60 & $0.48-0.74$ \\
\hline Incontinence & 32.1 & 39.7 & 0.001 & 0.72 & $0.59-0.88$ & 0.71 & $0.57-0.88$ \\
\hline \multicolumn{8}{|l|}{ Medication information } \\
\hline \multicolumn{8}{|l|}{$\overline{\text { Number of (mean+range) }}$} \\
\hline Medications & $9.0[0-22]$ & $7.0[1-22]$ & $P<0.001$ & 1.15 & $1.12-1.19$ & & \\
\hline Chronic medications & $7.7[0-22]$ & $6.2[0-22]$ & $P<0.001$ & 1.18 & $1.15-1.22$ & & \\
\hline Use of psychotropic's(\%) & 100.0 & 54.6 & $P<0.001$ & & & & \\
\hline Antipsychotics & 35.0 & 30.8 & 0.065 & 1.21 & $0.99-1.48$ & & \\
\hline Antidepressants & 48.3 & 32.4 & $P<0.001$ & 1.95 & $1.61-2.37$ & & \\
\hline
\end{tabular}

* $\mathrm{P}$ value of the difference between user and non-user using $\chi^{2}$ for categorical variables and independent $\mathrm{t}$-test for continuous variables

**odds ratio: Risk of taking a BZD/Z

*** stepwise regression model (covariates: gender,constipation,depression,pain,dementia,incontinence) 
TABLE 6 : Comparison of characteristics of chronic benzodiazepine and z-drug users for the indications 'insomnia', 'anxiety' and 'unrest'.

\begin{tabular}{|c|c|c|c|c|}
\hline RESIDENT CHARACTERISTICS & $\begin{array}{l}\text { Chronic BZD/Z } \\
\text { user INSOMNIA } \\
\quad(n=354)^{*}\end{array}$ & $\begin{array}{c}\text { Chronic BZD/Z } \\
\text { user ANXIETY } \\
\quad(n=105)^{*}\end{array}$ & $\begin{array}{c}\text { Chronic BZD/Z } \\
\text { user UNREST } \\
(n=63)^{*}\end{array}$ & $P$ value ** \\
\hline \multicolumn{5}{|l|}{ Demographical } \\
\hline Age (mean+range) & $85.5[60-102]$ & 84.9 [60-99] & $83.6[60-103]$ & 0.224 \\
\hline Gender(\% female) & 80.5 & 78.8 & 74.6 & 0.562 \\
\hline \multicolumn{5}{|l|}{ Main care problems(\%) } \\
\hline Constipation & 47.0 & 54.3 & 49.2 & 0.423 \\
\hline Risk of falling & 48.0 & 51.9 & 50.8 & 0.752 \\
\hline Depression & 36.3 & 61.2 & 28.3 & $P<0.001$ \\
\hline Chronic pain & 41.6 & 47.6 & 44.4 & 0.542 \\
\hline Dementia & 36.0 & 43.1 & 41.9 & 0.343 \\
\hline Incontinence & 31.5 & 28.8 & 33.3 & 0.811 \\
\hline \multicolumn{5}{|l|}{ Medication information } \\
\hline \multicolumn{5}{|l|}{ Number of (mean+range) } \\
\hline Medications & $8.4[1-20]$ & $10.0[2-21]$ & $9.1[3-17]$ & $P<0.001$ \\
\hline Chronic medications & $7.5[1-16]$ & $8.9[2-21]$ & $8.1[3-15]$ & $P<0.001$ \\
\hline \multicolumn{5}{|l|}{ Use of psychotropic's(\%) } \\
\hline Antipsychotics & 25.4 & 38.1 & 34.9 & 0.024 \\
\hline Antidepressants & 39.5 & 61.9 & 36.5 & $P<0.001$ \\
\hline
\end{tabular}

* residents receiving a single $B Z D / Z$ for this specific indication

** $\mathrm{P}$ value of differences using $\chi^{2}$ for dichotomous variates and one way Anova for continuous variates 
FIGURE 1: Indication split benzodiazepine and z-drug use in relation to increasing dementia.

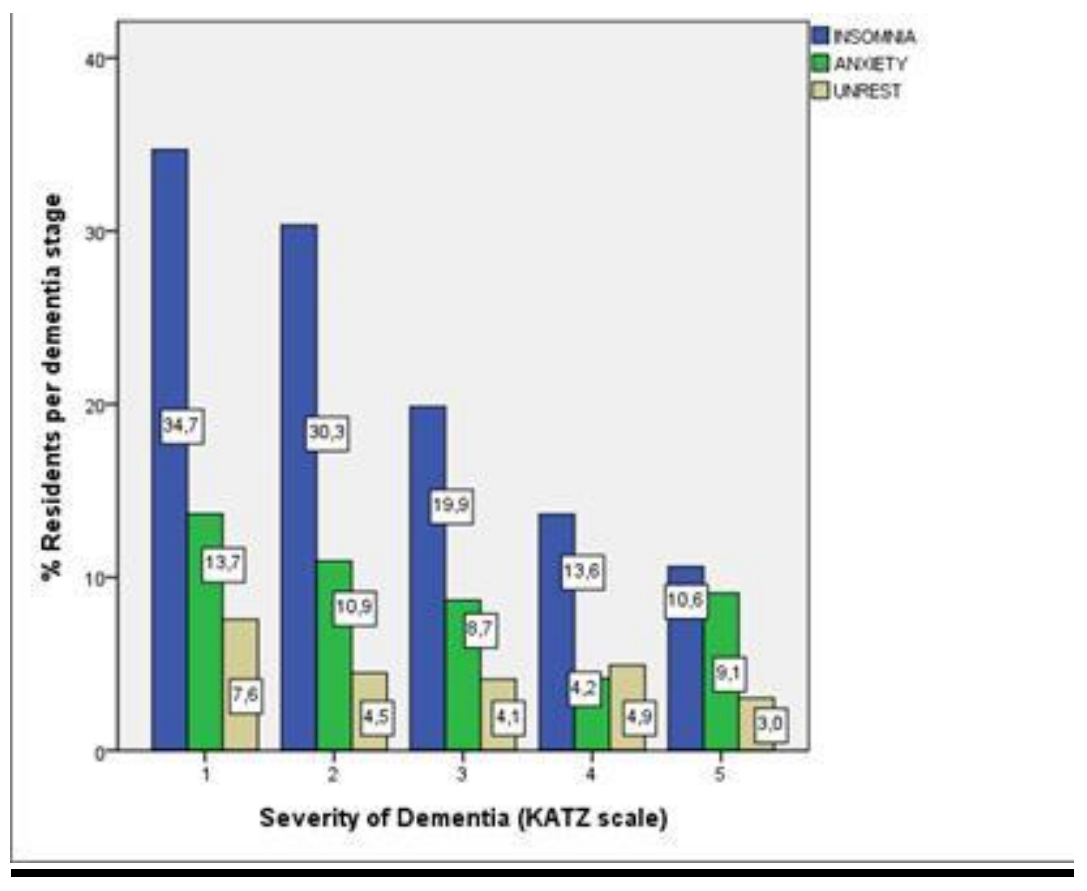

DEMENTIA STAGES (KATZ)

Stage 1: no dementia $(n=542)$

Stage $2(n=402)$

Stage $3(n=438)$

Stage $4(n=264)$

Stage 5: severe dementia $(n=66)$ 


\title{
Box:
}

\section{GERIATRIC UPPER LIMIT}

We based our selected dose adaptations on 3 formularia and 3 explicit criteria about inappropriate prescribing in the elderly:

formularia

Britisch National Formularium (BNF) (United Kingdom)

explicit criteria

the Martindale 36ste edition (2009)

Informatorium medicamentorum 2009 (the Netherlands)

\author{
BEERS 2003 (USA) \\ Rancourt 2004 (Canada) \\ Laroche 2007 (France)
}

Recommended daily doses were investigated for the most relevant BZD/Z and for the indications insomnia and anxiety.

\begin{tabular}{|c|c|c|c|c|c|c|c|c|}
\hline \multicolumn{9}{|c|}{ RECOMMENDED DAILY DOSES NOT TO EXCEED IN OLDER ADULTS } \\
\hline Sources & $\begin{array}{r}\text { LORAZ } \\
\text { insomnia }\end{array}$ & $\begin{array}{l}\text { EPAM } \\
\text { anxiety }\end{array}$ & $\begin{array}{c}\text { ALPRAZOLAM } \\
\text { anxiety }\end{array}$ & $\begin{array}{l}\text { BROMAZEPAM } \\
\text { anxiety }\end{array}$ & $\begin{array}{l}\text { PRAZEPAM } \\
\text { anxiety }\end{array}$ & $\begin{array}{l}\text { LORMETAZEPAM } \\
\text { insomnia }\end{array}$ & $\begin{array}{c}\text { ZOLPIDEM } \\
\text { insomnia }\end{array}$ & $\begin{array}{l}\text { ZOPICLONE } \\
\text { insomnia }\end{array}$ \\
\hline BNF & $1 \mathrm{mg}$ & $2 \mathrm{mg}$ & $0.75 \mathrm{mg}$ & $*$ & $*$ & $0.5 \mathrm{mg}$ & $5 \mathrm{mg}$ & $3.75 \mathrm{mg}$ \\
\hline Martindale & $2 \mathrm{mg}$ & $3 \mathrm{mg}$ & $0.75 \mathrm{mg}$ & $9 m g$ & $30 \mathrm{mg}$ & $0.5 \mathrm{mg}$ & $5 \mathrm{mg}$ & $3.75 \mathrm{mg}$ \\
\hline Inform. Medica & $2 \mathrm{mg}$ & $4 \mathrm{mg}$ & $0.75 \mathrm{mg}$ & $10 \mathrm{mg}$ & $30 \mathrm{mg}$ & $1 \mathrm{mg}$ & $*$ & $3.75 \mathrm{mg}$ \\
\hline BEERS & $*$ & $3 m g$ & $2 \mathrm{mg}$ & $*$ & $*$ & $*$ & $*$ & $*$ \\
\hline Rancourt & * & $3 m g$ & $0.75 \mathrm{mg}$ & $*$ & $*$ & $*$ & $*$ & $*$ \\
\hline Laroche & * & $3 \mathrm{mg}$ & $2 \mathrm{mg}$ & $*$ & * & $0.5 \mathrm{mg}$ & $5 \mathrm{mg}$ & $3.75 \mathrm{mg}$ \\
\hline $\begin{array}{l}\text { Geriatric upper } \\
\text { limit (in } \mathrm{mg} / \text { day) }\end{array}$ & $2 \mathrm{mg}$ & $3 \mathrm{mg}$ & $0.75 \mathrm{mg}$ & $10 \mathrm{mg}$ & $30 \mathrm{mg}$ & $0.5 \mathrm{mg}$ & $5 \mathrm{mg}$ & $3.75 \mathrm{mg}$ \\
\hline \multicolumn{9}{|c|}{ Geriatric upper limit expressed in } \\
\hline - DDD & 0,8 & 1,2 & 0,75 & 1 & 1 & 0,5 & 0,5 & 0,5 \\
\hline $\begin{array}{l}\text { - Diazepam } \\
\text { equivalent }\end{array}$ & $20 \mathrm{mg}$ & $30 \mathrm{mg}$ & $15 \mathrm{mg}$ & $20 \mathrm{mg}$ & $20 \mathrm{mg}$ & $3,3 \mathrm{mg}$ & $2,5 \mathrm{mg}$ & $2,5 \mathrm{mg}$ \\
\hline
\end{tabular}

* the BZD has no recommended doses for this indication or the BZD/ Z is not listed in the formularium/explicit criteria 


\section{References}

1 Azermai M, Elseviers M, Petrovic M, Van Bortel L, Stichele RV (2011) Geriatric drug utilisation of psychotropics in Belgian nursing homes. Hum Psychopharmacol DOI 10.1002/hup.1160

2 Gobert M, D'Hoore W (2005) Prevalence of psychotropic drug use in nursing homes for the aged in Quebec and in the French-speaking area of Switzerland. International Journal of Geriatric Psychiatry 20 (8): 712-721 DOI 10.1002/gps.1349

3 Hosia-Randell H, Pitkala K (2005) Use of psychotropic drugs in elderly nursing home residents with and without dementia in Helsinki, Finland. Drugs \& Aging 22 (9): 793-800 DOI 2298 [pii]

$4 \quad$ Petek Ster M, Cedilnik Gorup E (2011) Psychotropic medication use among elderly nursing home residents in Slovenia: cross-sectional study. Croat Med J 52 (1): 16-24

Ashton H (1994) GUIDELINES FOR THE RATIONAL USE OF BENZODIAZEPINES - WHEN AND WHAT TO USE. Drugs 48 (1): 25-40

$6 \quad$ Neutel $\mathrm{Cl}$ (2005) The epidemiology of long-term benzodiazepine use. Int Rev Psychiatry 17 (3): 189-197 DOI K4246L51U2309218 [pii] 10.1080/09540260500071863

7 Canadian Agency for Drugs and Technologies in Health (CADTH). Benzodiazepines in Older Adults: A Review of Clinical Effectiveness, Cost-Effectiveness, and Guidelines. 2010.AVAILABLE from http://www.cadth.ca/media/pdf:M0022_Benzodiazepines_Elderly.pdf. accessed: 10 August 2011

8 National Institute for Health an Clinical Excellence (NICE). Generalised anxiety disorder and panic disorder (with or without agoraphobia) in adults.January 2011. guidelines. Available from: http//www.nice.org.uk/nicemedia/live/13314/52599/52599.pdf. Accessed 10 August, 2011.

9 Martin JL, Sainz-Pardo M, Furukawa TA, Martin-Sanchez E, Seoane T, Galan C (2007) Benzodiazepines in generalized anxiety disorder: heterogeneity of outcomes based on a systematic review and meta-analysis of clinical trials. Journal of Psychopharmacology 21 (7): 774782 DOI 21/7/774 [pii] 10.1177/0269881107077355

Beland SG, Preville M, Dubois MF, Lorrain D, Voyer P, Bosse C, Grenier S, Moride Y (2010) The association between length of benzodiazepine use and sleep quality in older population. International Journal of Geriatric Psychiatry DOI 10.1002/gps.2623

Lader M, Tylee A, Donoghue J (2009) Withdrawing benzodiazepines in primary care. Cns Drugs 23 (1): 19-34 DOI 10.2165/0023210-200923010-00002 2312 [pii]

12 Voyer P, Preville M, Cohen D, Berbiche D, Beland SG (2010) The prevalence of benzodiazepine dependence among community-dwelling older adult users in Quebec according to typical and atypical criteria. Can J Aging 29 (2): 205-213 DOI S0714980810000115 [pii] $10.1017 /$ S0714980810000115 
13 Verdoux $H$, Lagnaoui $\mathrm{R}$, Begaud B (2005) Is benzodiazepine use a risk factor for cognitive decline and dementia? A literature review of epidemiological studies. Psychological Medicine 35 (3): 307-315 DOI 10.1017/s0033291704003897

14 Wu CS, Wang SC, Chang IS, Lin KM (2009) The Association Between Dementia and Long-Term Use of Benzodiazepine in the Elderly: Nested Case-Control Study Using Claims Data. American Journal of Geriatric Psychiatry 17 (7): 614-620

Barker MJ, Greenwood KM, Jackson M, Crowe SF (2004) Cognitive effects of long-term benzodiazepine use - A meta-analysis. Cns Drugs 18 (1): 37-48

Klotz U (1998) Effect of age on pharmacokinetics and pharmacodynamics in man. International Journal of Clinical Pharmacology and Therapeutics 36 (11): 581-585

Petrovic M, Mariman A, Warie H, Afschrift M, Pevernagie D (2003) Is there a rationale for prescription of benzodiazepines in the elderly? Review of the literature. Acta Clin Belg 58 (1): 2736

18 Madhusoodanan S. BOJ (2004) Safety of benzodiazepines in the geriatric population. Expert Opinion on Drug Safety 3 (5): 485-493

19 Cook PJ, Huggett A, Graham-Pole R, Savage IT, James IM (1983) Hypnotic accumulation and hangover in elderly inpatients: a controlled double-blind study of temazepam and nitrazepam. $\mathrm{Br}$ Med J (Clin Res Ed) 286 (6359): 100-102

Mustard CA, Mayer T (1997) Case-control study of exposure to medication and the risk of injurious falls requiring hospitalization among nursing home residents. Am J Epidemiol 145 (8): 738-745

The British National Formularium (BNF). British Medical Association and the Royal Pharmaceutical Society. Available from http://bnf.org:bnf:index.htm Accessed 10 August 2011

KNMP. Royal Dutch Society of Pharmacy [in Dutch: Informatorium Medicametorum. Koninklijke Nederlandse Maatschappij ter bevordering van de Farmacie] (2009) Available from:

www.knmp.nl Accessed 8 June 2011

The Martindale: The Complete Drug Reference, $36^{\text {th }}$ edition. Sweetman S.C. editor: Pharmaceutical Press.

Fick DM, Cooper JW, Wade WE, Waller JL, Maclean JR, Beers MH (2003) Updating the Beers criteria for potentially inappropriate medication use in older adults: results of a US consensus panel of experts. Arch Intern Med 163 (22): 2716-2724 DOI 10.1001/archinte.163.22.2716163/22/2716 [pii]

25 Rancourt C MJ, Baillargeon L, Verreault R, Laurin D, Grégoire JP. (2004) Potentially inappropriate prescriptions for older patients in long-term care. BMC Geriatrics 4 (9) 
Laroche ML, Charmes JP, Merle L (2007) Potentially inappropriate medications in the elderly: a French consensus panel list. European Journal of Clinical Pharmacology 63 (8): 725-731 DOI 10.1007/s00228-007-0324-2

27 Stevenson DG, Decker SL, Dwyer LL, Huskamp HA, Grabowski DC, Metzger ED, Mitchell SL (2010) Antipsychotic and Benzodiazepine Use Among Nursing Home Residents: Findings From the 2004 National Nursing Home Survey. American Journal of Geriatric Psychiatry 18 (12): 1078-1092 DOI 10.1097/JGP.0b013e3181d6c0c6

28 Holmquist IB, Svensson B, Hoglund P (2003) Psychotropic drugs in nursing- and old-age homes: relationships between needs of care and mental health status. European Journal of Clinical Pharmacology 59 (8-9): 669-676 DOI 10.1007/s00228-003-0679-y

Elseviers M. VSR, Soenen K., Gobert M., Van Bortel L., Van De Voorde C. (2010) Drug utilisation in Belgian nursing homes: impact of residents' and institutional characteristics. Pharmacoepidemiol Drug Safety 19: 1041-1048

Katz S, Akpom CA (1976) 12. Index of ADL. Med Care 14 (5 Suppl): 116-118

31 ATC/DDD system. WHO Collaborating Centre for Drug Statistics Methodology.2009; available from: http://www.whocc.no Accessed 20June 2011

32 Westbury J, Jackson S, Gee P, Peterson G (2010) An effective approach to decrease antipsychotic and benzodiazepine use in nursing homes: the RedUse project. International Psychogeriatrics 22 (1): 26-36 DOI 10.1017/s1041610209991128

33 Bartlett G, Abrahamowicz M, Tamblyn R, Grad R, Capek R, du Berger R (2004) Longitudinal patterns of new Benzodiazepine use in the elderly. Pharmacoepidemiology and Drug Safety 13 (10): 669-682 DOI 10.1002/pds.908

34 Gallagher P, Ryan C, Byrne S, Kennedy J, O'Mahony D (2008) STOPP (Screening Tool of Older Person's Prescriptions) and START (Screening Tool to Alert Doctors to Right Treatment). Consensus validation. International Journal of Clinical Pharmacology and Therapeutics 46 (2): 72 83

BCFI (2010) Belgian Centre for Pharmacotherapeutic information. available from http://www.bcfi.be/ Accessed 8 June 2011

B Terluin FBVH, K Van der Meer, G J H Neomagus, J Hekman, L P J Aulbers, J S Starreveld and M H Grol (2009) NHG-Standaarden Angststoornissen In: NHG-Standaarden voor huisartsened. Nederlandse huisartsen genootschap.

37 Morin AK (2006) Strategies for treating chronic insomnia. Am J Manag Care 12 (8 Suppl): S230245 DOI 3137 [pii] 
van Vliet P, van der Mast RC, van den Brock M, Westendorp RGJ, de Craen AJM (2009) Use of benzodiazepines, depressive symptoms and cognitive function in old age. International Journal of Geriatric Psychiatry 24 (5): 500-508 DOI 10.1002/gps.2143

Kripke DF (2007) Greater incidence of depression with hypnotic use than with placebo. BMC Psychiatry 7: 42 DOI 1471-244X-7-42 [pii] 10.1186/1471-244X-7-42

Bliwise DL (2004) Sleep disorders in Alzheimer's disease and other dementias. Clin Cornerstone 6 Suppl 1A: S16-28

Cook JM, Marshall R, Masci C, Coyne JC (2007) Physicians' perspectives on prescribing benzodiazepines for older adults: a qualitative study. Journal of General Internal Medicine 22 (3): 303-307 DOI 10.1007/s11606-006-0021-3

42 Manji HK, Drevets WC, Charney DS (2001) The cellular neurobiology of depression. Nat Med 7 (5): 541-547 DOI 10.1038/87865 87865 [pii]

Cloos JM, Ferreira V (2009) Current use of benzodiazepines in anxiety disorders. Curr Opin Psychiatry 22 (1): 90-95 DOI 10.1097/YCO.0b013e32831a473d00001504-200901000-00016 [pii]

Ruths S, Straand J, Nygaard HA (2003) Multidisciplinary medication review in nursing home residents: what are the most significant drug-related problems? The Bergen District Nursing Home (BEDNURS) study. Qual Saf Health Care 12 (3): 176-180

Berdot S, Bertrand M, Dartigues JF, Fourrier A, Tavernier B, Ritchie K, Alperovitch A (2009) Inappropriate medication use and risk of falls--a prospective study in a large community-dwelling elderly cohort. BMC Geriatrics 9: 30 DOI 1471-2318-9-30 [pii]10.1186/1471-2318-9-30

Ensrud KE, Blackwell TL, Mangione CM, Bowman PJ, Whooley MA, Bauer DC, Schwartz AV, Hanlon JT, Nevitt MC (2002) Central nervous system-active medications and risk for falls in older women. J Am Geriatr Soc 50 (10): 1629-1637 DOI jgs50453 [pii]

47 Boyle N, Naganathan V, Cumming RG (2010) Medication and falls: risk and optimization. Clin Geriatr Med 26 (4): 583-605 DOI S0749-0690(10)00055-8 [pii]10.1016/j.cger.2010.06.007

48 Svarstad BL, Mount JK (2001) Chronic benzodiazepine use in nursing homes: effects of federal guidelines, resident mix, and nurse staffing. J Am Geriatr Soc 49 (12): 1673-1678 DOI 49278 [pii]

Anthierens S, Pasteels I, Habraken H, Steinberg P, Declercq T, Christiaens T (2010) Barriers to nonpharmacologic treatments for stress, anxiety, and insomnia Family physicians' attitudes toward benzodiazepine prescribing. Can Fam Phys 56 (11): E398-E406

50 Iliffe S, Curran HV, Collins R, Kee SCY, Fletcher S, Woods B (2004) Attitudes to long-term use of benzodiazepine hypnotics by older people in general practice: findings from interviews with service users and providers. Aging \& Mental Health 8 (3): 242-248 DOI $10.1080 / 13607860410001669778$ 
51 Cormack MA, Owens RG, Dewey ME (1989) The effect of minimal interventions by general practitioners on long-term benzodiazepine use. J R Coll Gen Pract 39 (327): 408-411

52 Gorgels WJ, Oude Voshaar RC, Mol AJ, van de Lisdonk EH, van Balkom AJ, van den Hoogen HJ, Mulder J, Breteler MH, Zitman FG (2005) Discontinuation of long-term benzodiazepine use by sending a letter to users in family practice: a prospective controlled intervention study. Drug and Alcohol Dependence 78 (1): 49-56 DOI S0376-8716(04)00261-3 [pii]10.1016/j.drugalcdep.2004.09.001

53 Denis C, Fatseas M, Lavie E, Auriacombe M (2006) Pharmacological interventions for benzodiazepine mono-dependence management in outpatient settings. Cochrane Database Syst Rev 3: CD005194 DOI 10.1002/14651858.CD005194.pub2

54 Morin CM, Bootzin RR, Buysse DJ, Edinger JD, Espie CA, Lichstein KL (2006) Psychological and behavioral treatment of insomnia:update of the recent evidence (1998-2004). Sleep 29 (11): 1398-1414

55 Mendelson WB (1995) Long-term follow-up of chronic insomnia. Sleep 18 (8): 698-701

56 Bain KT (2006) Management of chronic insomnia in elderly persons. Am J Geriatr Pharmacother 4 (2): 168-192 DOI S1543-5946(06)00028-6 [pii]10.1016/j.amjopharm.2006.06.006

57 Alessi CA, Schnelle JF (2000) Approach to sleep disorders in the nursing home setting. REVIEW ARTICLE. Sleep Med Rev 4 (1): 45-56 DOI S1087-0792(99)90066-7 [pii]10.1053/smrv.1999.0066

58 Lyne J, Quinlivan L, Byrne CA, Malone K, Walsh C (2011) Sleep hygiene use in a psychiatry outpatient setting. Ir Med J 104 (2): 49-50

59 Charlson F, Degenhardt L, McLaren J, Hall W, Lynskey M (2009) A systematic review of research examining benzodiazepine-related mortality. Pharmacoepidemiology and Drug Safety 18 (2): $93-$ 103 DOI 10.1002/pds.1694

60 Anthierens S, Grypdonck M, De Pauw L, Christiaens T (2009) Perceptions of nurses in nursing homes on the usage of benzodiazepines. J Clin Nurs 18 (22): 3098-3106 DOI JCN2758 [pii]10.1111/j.1365-2702.2008.02758.x

61 Verrue CL, Petrovic M, Mehuys E, Remon JP, Vander Stichele R (2009) Pharmacists' interventions for optimization of medication use in nursing homes : a systematic review. Drugs \& Aging 26 (1): 37-49 DOI 10.2165/0002512-200926010-000032613 [pii] 